\title{
Uji Kompor Gas Biomassa Menggunakan Berbagai Jenis Isolator Ditinjau dari Efisiensi Termal dengan Metode Water Boiling Test
}

\author{
Muhammad Hanif Darussalam ${ }^{* 1}$, Irawan Rusnadi², Zurohaina ${ }^{3}$ \\ ${ }^{1,2,3}$ Teknik Energi / Teknik Kimia, Politeknik Negeri Sriwijaya, Indonesia. \\ Email: ${ }^{1}$ hanifdarusalam@gmail.com, ${ }^{2}$ irawan_rusnadi@ polsri.ac.id
}

\begin{abstract}
Abstrak
Bahan bakar fosil merupakan sumber energi tak terbarukan yang akan mengakibatkan berkurangnya energi fosil, khususnya minyak bumi dan gas alam. Pemerintah Indonesia juga telah berkomitmen untuk melakukan transisi energi menuju dekarbonisasi pada tahun 2060 dengan beralih menuju energi baru terbarukan (EBT). Salah satu alternatif energi baru dan terbarukan yang dapat mengurangi konsumsi bahan bakar minyak dan gas yang diperoleh dari fosil adalah dengan menggunakan energi dari limbah biomassa seperti biopelet. Seiring dengan perkembangan penelitian dan produksi biopelet yang telah ada saat ini, dibutuhkan suatu alat yang mampu memaksimalkan penggunaan biopelet seperti kompor gas biomassa, sehingga tujuan penelitian ini yaitu membuat kompor gas biomassa sesuai standar yang berlaku dengan mengetahui pemanasan air yang dihasilkan, serta mendapatkan jenis isolator terbaik dari sisi efisiensi termal. Pengujian kinerja kompor menggunakan metode water boiling test untuk mendapatkan nilai efisiensi termal, yaitu kompor digunakan untuk mendidihkan 5 liter air menggunakan bahan bakar biopelet yang diisi sebesar 75\% (1,2225 kg) kapasitas tabung bakar. Adapun variasi jenis isolator yang digunakan yaitu asbestos, rockwool, fiberglass, dan tanpa isolator.Variasi terbaik terdapat pada pengujian kompor dengan isolator fiberglass. Pada variasi tersebut, kompor gas biomassa mendidihkan 5 liter air dengan waktu 545 detik, temperatur dinding kompor $62^{\circ} \mathrm{C}$, dan efisiensi termal $27,48 \%$.
\end{abstract}

Kata kunci: Biopelet, Efisiensi Termal, Isolator, Kompor Gas Biomassa, Water Boiling Test.

\section{The Biomass Gas Stove Test Uses Various Types of Insulator in Terms of Thermal Efficiency with Water Boiling Test Method}

\begin{abstract}
Fossil fuels are non-renewable energy sources which will lead to a reduction in fossil energy, especially oil and natural gas. The Indonesian government has also committed to making an energy transition towards decarbonization by 2060 by switching to new and renewable energy (EBT). One of the new and renewable energy alternatives that can reduce the consumption of fuel oil and gas obtained from fossils is to use energy from biomass waste such as biopellets. Along with the development of research and production of existing biopellets, a tool is needed that is able to maximize the use of biopellets such as biomass gas stoves, so the purpose of this research is to make biomass gas stoves according to applicable standards by knowing the heating of the water produced, and getting the type of insulator. the best in terms of thermal efficiency. The performance test of the stove uses the water boiling test method to get the value of thermal efficiency, namely the stove is used to boil 5 liters of water using biopellet fuel filled with 75\% (1.2225 $\mathrm{kg}$ ) of the capacity of the combustion tube. The variations of the type of insulator used are asbestos, rockwool, fiberglass, and without insulator. The best variation is found in the stove test with fiberglass insulator. In this variation, the biomass gas stove boils 5 liters of water in 545 seconds, the stove wall temperature is $62^{\circ} \mathrm{C}$, and the thermal efficiency is $27.48 \%$.
\end{abstract}

Keywords: Biopellets, Biomass Gas Stove, Insulators, Thermal Efficiency, Water Boiling Test.

\section{PENDAHULUAN}

Produksi minyak bumi selama 10 tahun terakhir menunjukkan kecenderungan menurun, dari 346 juta barel pada tahun 2009 menjadi sekitar 283 juta barel pada tahun 2018 [1]. Menurut Kementerian Energi dan Sumber Daya Mineral (ESDM) bulan Januari 2021 melalui Menteri ESDM mengungkapkan bahwa cadangan minyak bumi di Indonesia akan tersedia hanya hingga 9,5 tahun mendatang dan cadangan gas bumi hanya hingga 19,9 
tahun mendatang dengan asumsi tidak ditemukan penemuan sumber migas baru dan mengikuti tingkat produksi saat ini.

Berkurangnya energi fosil terutama minyak bumi serta komitmen global dalam pengurangan emisi gas rumah kaca juga mendorong Pemerintah untuk meningkatkan peran energi baru dan terbarukan (EBT) secara terus menerus sebagai bagian dalam menjaga ketahanan dan kemandirian energi [1]. Salah satu energi baru dan terbarukan yang saat ini banyak dikembangkan dan diproduksi karena memiliki bahan baku yang sangat melimpah yaitu Biopelet.

Biopelet sebagai bahan bakar dapat digunakan dengan berbagai cara maupun alat. Salah satunya yaitu pembakaran biopelet menggunakan kompor biomassa untuk menanggulangi permasalahan dari emisi gas yang berbahaya bagi kesehatan dan lingkungan. Kompor gas-biomassa (biomass gas-fired stove) merupakan salah satu pilihan kompor sederhana dan merupakan jenis kompor yang berpotensi untuk dikembangkan menggantikan maupun mendampingi keberadaan kompor minyak tanah dan kompor gas LPG untuk menghemat penggunaan minyak bumi serta gas alam [2].

Kompor biomassa yang berbahan bakar biopelet biasanya memiliki desain yang sederhana yaitu menggunakan sistem top-lit updraft (TLUD) gasification yang terdiri dari mekanisme pembakaran secara preheating, counter-flow, dan co-firing [3]. Pada prinsip TLUD, terdapat proses pirolisa yang mendekomposisi biopelet menjadi karbon, tar, minyak, gas dan produk pirolisa lainnya secara endotermis [4].Penggunaan isolator membantu agar tidak banyak panas yang keluar dari kompor untuk mendukung proses endotermik yang membutuhkan panas didalam prosesnya [5].

Sehingga yang perlu diteliti lebih jauh dari pembuatan alat kompor gas biomassa dengan memvariasikan jenis isolator adalah hasil dari proses pembakaran biopelet untuk merebus air pada kompor guna mengetahui performa kompor yang ditinjau berdasarkan efisiensi termal agar dapat menciptakan kompor yang optimal.

\section{METODE PENELITIAN}

Pada penelitian ini menggunakan seperangkat Kompor Gas Biomassa, Gelas Kimia, Neraca, Termometer, Termo Gun, Penjepit Besi, Panci, Kain, Stopwatch, Pemantik Api, Isolator Asbestos, Rockwool, dan Fiberglass.

Bahan yang digunakan yaitu Biopelet yang terbuat dari campuran kayu mahoni, sengon, dan akasia yang diperoleh ditempat yang sama, serta Air.

Pada penelitian ini, terdapat beberapa tahapan perlakuan yang dilakukan, diantaranya:

a. Tahap Persiapan Bahan Baku dan Alat

Biopelet yang merupakan bahan baku diperoleh dari industri pabrik biopelet yang berada di kota Tangerang sebesar $50 \mathrm{~kg}$. Sampel biopelet diserahkan untuk diuji nilai kalor (ASTM D5865-11a) dan dilakukan analisa proksimat seperti analisa kadar air, karbon tetap, kadar abu, dan zat terbang (ASTM D7582-10) di Laboratorium Teknik Kimia Politeknik Negeri Sriwijaya. Alat yang digunakan yaitu kompor gas biomassa yang dapat dilihat pada Gambar 1. Isolator yang digunakan memiliki ketebalan yang sama sebesar $3 \mathrm{~mm}$ untuk setiap percobaan.

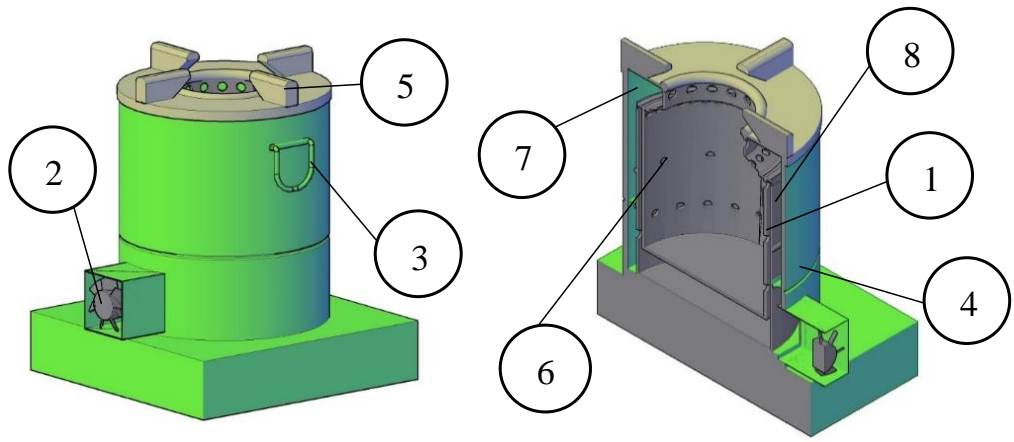

Gambar 1. Kompor Gas Biomassa

b. Uji Kinerja Kompor Gas Biomassa

Pada tahapan ini yaitu air sebanyak 5 liter yang diketahui temperatur awalnya ditampung pada sebuah panci dan dipanaskan diatas kompor gas biomassa berbahan bakar biopelet sebesar $75 \%$ kapasitas unggun (1222,5 gr) yang telah diukur temperatur dinding awal sebelumnya. Tahapan ini dilakukan hingga air 
mendidih dan didapat data boiling time, massa air dan biopelet akhir, temperatur dinding kompor akhir.

Tahapan diulang dengan mengganti jenis isolator yang akan digunakan.

c. Analisis Data

- Boiling Time

Boiling time merupakan waktu yang dibutuhkan untuk memanaskan air pada alat masak. Waktu dihitung saat meletakkan panci pada tungku yang sudah menyala dengan stabil hingga air mendidih pada suhu sekitar $100^{\circ} \mathrm{C}$.

- $\quad$ Temperatur Dinding

Temperatur dinding kompor akan meningkat seiring berjalannya waktu perebusan.

- Efisiensi Termal

Efisiensi termal merupakan rasio perbandingan kalor yang dihasilkan oleh bahan bakar terhadap kalor yang diterima oleh air untuk menaikkan suhunya dan menguapkannya.

$$
\eta_{\mathrm{T}}=\frac{\max C p \times \Delta T+\Delta \max L}{\Delta \operatorname{mk} \times L H V} \times 100 \%
$$

Keterangan :

$\mathrm{m}_{\mathrm{a}}$ adalah massa air (dalam kilogram)

$\mathrm{C}_{\mathrm{p}}$ adalah kalor jenis air $\left(4,1866 \mathrm{~kJ} / \mathrm{kg}^{\circ} \mathrm{C}\right)$

$\Delta \mathrm{T}$ adalah selisih suhu akhir air terhadap suhu awal air

$\Delta \mathrm{m}_{\mathrm{a}}$ adalah massa air yang menguap

$\mathrm{L}$ adalah kalor penguapan air

$\Delta \mathrm{m}_{\mathrm{k}}$ adalah massa bahan bakar yang telah digunakan

LHV adalah nilai kalor netto bahan bakar

\section{HASIL DAN PEMBAHASAN}

Dari penelitian yang telah dilakukan, didapatkan data hasil pengamatan pada uji perebusan dengan variasi jenis isolator. Data hasil dan pembahasan sebagai berikut.

\subsection{Pengaruh Jenis Isolator Terhadap Boiling Time}

Boiling time merupakan waktu yang dibutuhkan untuk memanaskan air pada alat masak. Waktu dihitung saat meletakkan panci pada tungku yang sudah menyala dengan stabil hingga air mendidih pada suhu sekitar $100^{\circ} \mathrm{C}$. Hasil penelitian diperoleh grafik hubungan antara jenis isolator terhadap boiling time seperti pada Gambar 2.

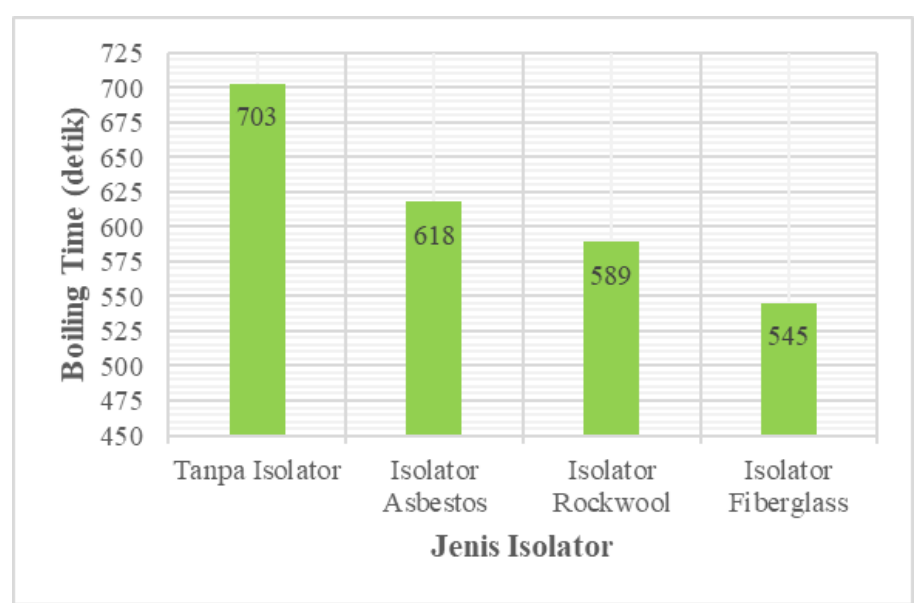

Gambar 2. Grafik pengaruh jenis isolator terhadap boiling time

Berdasarkan Gambar 2, dapat diketahui bahwa boiling time tanpa menggunakan isolator akan memakan waktu lebih lama dibandingkan dengan kompor yang telah dipasang isolator.

Waktu yang dibutuhkan untuk mendidihkan $5 \mathrm{~kg}$ air (boiling time) paling cepat adalah jenis isolator fiberglass dengan waktu 545 detik, diikuti isolator jenis rockwool dengan waktu 589 detik, dan isolator serat asbestos dengan waktu 618 detik. 


\subsection{Pengaruh Jenis Isolator Terhadap Temperatur Dinding Kompor}

Temperatur dinding kompor diukur menggunakan thermogun khusus untuk keteknikan. Diagram dapat dilihat pada Gambar 3.

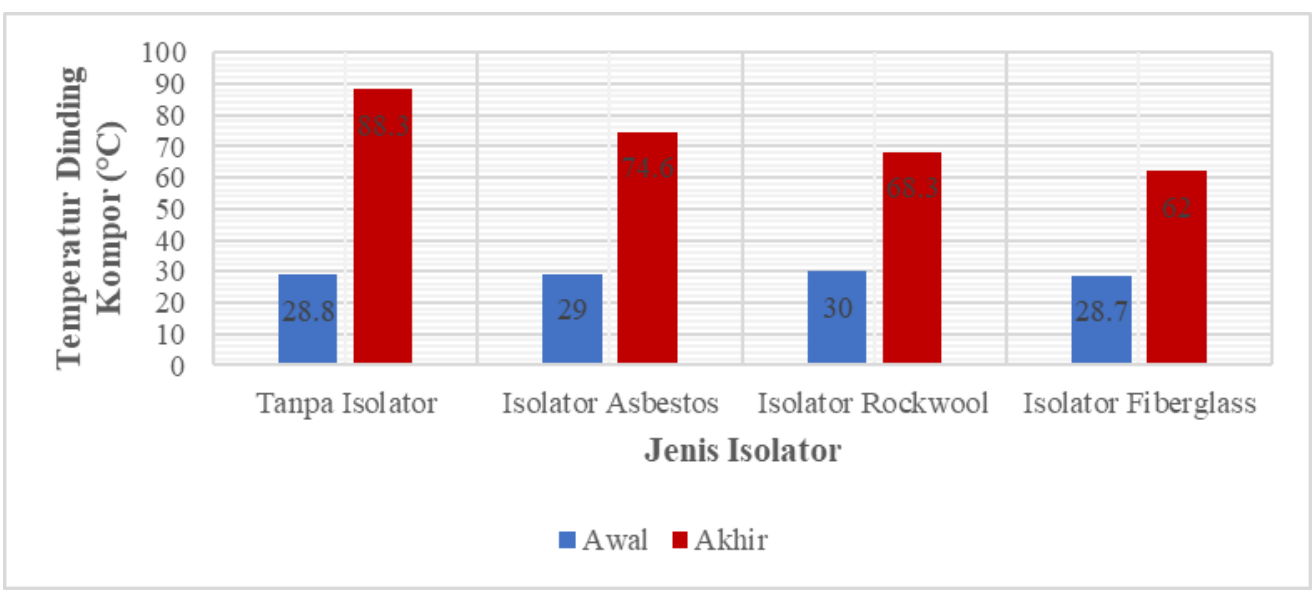

Gambar 3. Grafik hubungan jenis isolator terhadap temperatur dinding kompor

Temperatur awal dinding kompor setiap percobaan jenis isolator berada pada temperatur lingkungan dengan kisaran $28,7^{\circ} \mathrm{C}$ hingga $30^{\circ} \mathrm{C}$ dan setelah dilakukan pengujian alat, kompor tanpa menggunakan isolator menunjukkan suhu dinding tertinggi dengan nilai $88,3^{\circ} \mathrm{C}$ diikuti dengan isolator serat asbestos dengan suhu $74,6^{\circ} \mathrm{C}$, lalu dengan isolator rockwool bersuhu $68,3^{\circ} \mathrm{C}$, dan isolator fiberglass yang mempunyai konduktivitas termal paling kecil sebagai temperatur terendah pada dinding akhir dengan suhu $62^{\circ} \mathrm{C}$.

\subsection{Pengaruh Jenis Isolator Terhadap Efisiensi Termal}

Efisiensi termal merupakan rasio perbandingan kalor yang dihasilkan oleh bahan bakar terhadap kalor yang diterima oleh air untuk menaikkan suhunya dan menguapkannya.

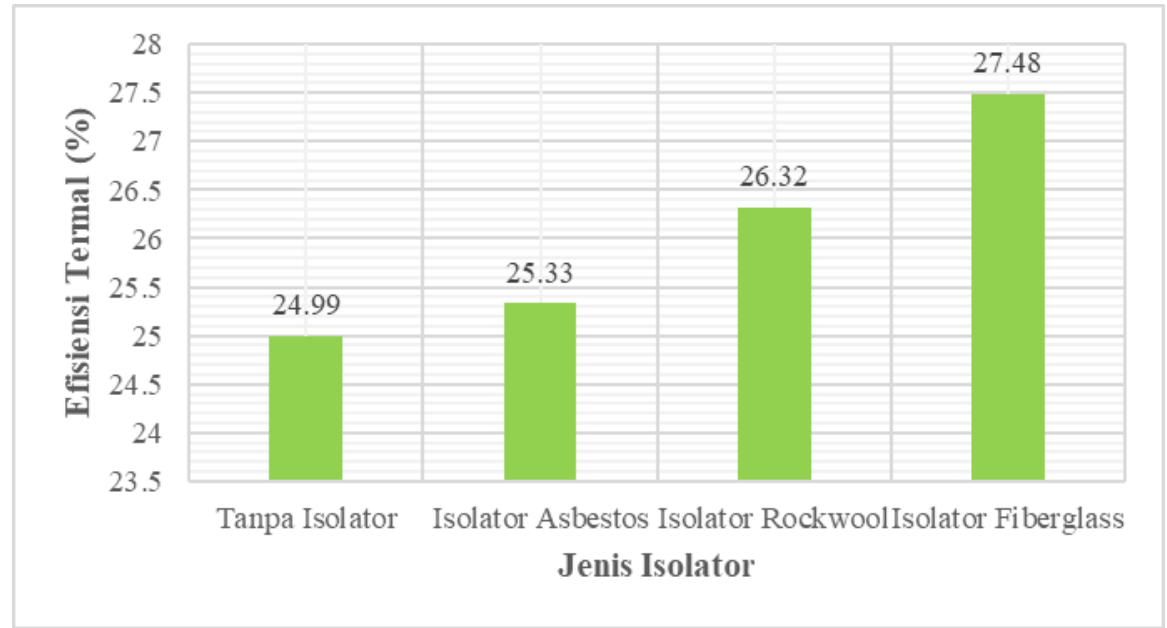

Gambar 4. Grafik hubungan jenis isolator terhadap Efisiensi Termal

Dari Gambar 4, efisiensi termal kompor tanpa isolator lebih kecil dibandingkan kompor dengan isolator. Nilai efisiensi termal kompor tanpa isolator sebesar 24,99\%. Untuk nilai kompor menggunakan isolator asbestos dan rockwool berturut-turut $25,33 \%$ dan $26,32 \%$. Sedangkan nilai efisiensi terbesar berada pada kompor dengan isolator fiberglass dengan nilai $27,48 \%$. Secara teori, isolator fiberglass lebih unggul pada nilai konduktivitas termal dibanding isolator rockwool dan isolator asbestos dengan nilai berturut-turut 0,0372 W/m.K, 0,0465 $\mathrm{W} / \mathrm{m} . \mathrm{K}$, dan $0,1105 \mathrm{~W} / \mathrm{m} . \mathrm{K}$ [6]. Semua jenis variabel penelitian tetap memenuhi efisiensi termal yang ditetapkan oleh Badan Standarisasi Nasional (BSN) yang diatur dalam SNI 7926-2013 tentang kinerja tungku biomassa dengan nilai efisiensi termal minimal 20\% [7]. 


\subsection{Pengaruh Jenis Isolator Terhadap Kompor Gas Biomassa}

Berdasarkan penelitian yang telah dilakukan, penggunaan berbagai jenis isolator dapat mempengaruhi hasil dari pengujian water boiling test pada kompor gas biomassa. Penggunaan isolator merupakan hal yang sangat positif dan membantu dalam mempersingkat boiling time hingga 158 detik lebih cepat, menurunkan temperatur dinding kompor hingga $26^{\circ} \mathrm{C}$ lebih dingin, dan meningkatkan efisiensi termal kompor gas biomassa hingga 2,49\% lebih tinggi dibandingkan dengan kompor gas biomassa yang tidak menggunakan isolator.

\section{KESIMPULAN}

Alat kompor gas biomassa yang diuji telah memenuhi nilai minimum efisiensi termal sebesar $20 \%$ yang ditetapkan oleh BSN yang tertuang dalam SNI 7926-2013 tentang kinerja tungku biomassa walaupun tidak menggunakan isolator. Namun penggunaan isolator terbukti dapat mempercepat waktu memasak dan menurunkan temperatur dinding luar kompor. Bahkan dengan digunakannya Isolator fiberglass, mampu meningkatkan efisiensi kompor dari $24,99 \%$ menjadi $27,48 \%$ atau dengan kata lain efisiensi meningkat sebesar $9,06 \%$ dibanding kompor tanpa menggunakan isolator.

\section{DAFTAR PUSTAKA}

[1] Tim Sekretaris Jenderal Dewan Energi Nasional, Outlook Energi Indonesia 2019. Sekretariat Jenderal Dewan Energi Nasional, 2019.

[2] M. A. Zakariya, M. A. Irfa'i, dan M. M. Rosadi, "Analisis pengaruh variasi bahan bakar terhadap uji efektivitas kompor biomassa," ARMATUR Artik. Tek. Mesin Manufaktur, vol. 1, no. 2, hlm. 55-60, Sep 2020, doi: 10.24127/armatur.v1i2.310.

[3] Giyanto, "Kajian Preferensi Penggunaan Kompor Biomassa Pelet Kayu Sebagai Alternatif Pengganti Tungku Tradisional," Pros. Semin. Nas. NCIET, vol. 1, 2020.

[4] E. Karmiza, S. Helianty, dan Zulfansyah, "Evaluasi Kinerja Kompor UB-03-1 Berbahan Bakar Limbah Industri Kayu Olahan, Tempurung Kelapa, Pelepah Sawit, dan Ranting Kayu Akasia," Jom FTEKNIK, vol. 1, 2014.

[5] M. S. Ummami, "Pengaruh Ukuran Partikel dan Kecepatan Udara Terhadap Performa Kompor Gasifikasi Top Lit Up-Draft dengan Bahan Bakar Campuran Sekam Padi dan Serbuk Kayu,” Skripsi, Universitas Muhammadiyah Surakarta, Surakarta, 2018.

[6] C. P. Kothandaraman dan S. Subramanyan, Heat and Mass Transfer Data Book, 6 ed. New Delhi: New Age International Publishers, 2007.

[7] Panitia Teknis Bioenergi, Kinerja Tungku Biomassa. Badan Standarisasi Nasional, 2013. 